\title{
THE IMPORTANCE OF INDIVIDUAL CLINICAL AND LABORATORY INDICA- TORS IN THE DIFFERENTIAL DIAGNOSIS OF POSTPARTUM SEPTIC COMPLI- CATIONS
}

Varahabhatla Vamsi ${ }^{1}$, Vinisha Tekwani ${ }^{1}$, Pavliuchenko Myhaelo Ivanovich ${ }^{2}$

${ }^{1}$ Zaporozhye State Medical University, Zaporozhye, UKRAINE

${ }^{2}$ Department of Obstetrics and Gynecology, Zaporozhye State Medical University, Zaporozhye, UKRAINE

\section{ABSTRACT}

Aims: To perform a comparative analysis of individual clinical and laboratory indicators in the differential diagnosis of conditionally limited and generalized forms of postpartum septic complications.

Methods: The study included 34 patients at Gynecology Department of the Zaporizhzhia Regional Clinical Hospital from 2013 to 2016 with postpartum purulent-septic diseases. Patients were divided into 2 groups. Group I consisted of 15 women who were diagnosed with a conditionally limited postpartum purulent-inflammatory disease (endometritis). Group II included 19 women with generalized forms of postpartum purulent-inflammatory diseases (peritonitis, sepsis). For the diagnosis of Multiple Organ Failure due to sepsis, we used the Sequential (Sepsis-Related) Organ Failure Assessment and quick Sequential (Sepsis-Related) Organ Failure Assessment. The differences between the first and second group were assessed by using the Mann-Whitney U test and STATISTICA Version 10.

Results: Body temperature was increased in all 34 patients. The average heart rate in group I was $91.6 \pm 8.35$ beats/ min and $102.26 \pm 16.42$ beats/min in group II. The average respiratory rate was $19.07 \pm 2.49$ breaths/min in group I and $24.16 \pm 5.09$ breaths/min in group II. In group I, none of the patients scored a total of two or more points on the Sequential (Sepsis-Related) Organ Failure Assessment and quick Sequential (Sepsis-Related) Organ Failure Assessment scales; in group II, there were $5(26.32 \%)$ patients who had scored two points or more on the Sequential (Sepsis-Related) Organ Failure Assessment scale; and 2 (10.53\%) patients had scored 2 points or more in the quick Sequential (Sepsis-Related) Organ Failure Assessment scale.

Conclusion: Clinical cases of postpartum period with inflammation of uterus and signs of multiple organ failure should be; regarded as a septic state, assessed by the Sequential (Sepsis-Related) Organ Failure Assessment scale as they require urgent medical help.

Keywords: Postpartum period, endometritis, sepsis, peritonitis, multiple organ failure

\section{INTRODUCTION}

With the implementation of regulations and guidelines set by WHO, the global maternal mortality ratio decreased from 385 to 216 deaths per 100,000 live births from the year 1990 to 2015, but still conditions need to be moderated (1). According to authors Lapinsky and Slynko et al. $(2,3)$ complications of infections occupy the third place among the causes of maternal mortality with a rate up to $10 \%$.

In the United Kingdom, despite significant advances in diagnostics, medical management and use of advanced capabilities of antimicrobial therapy, postpartum sepsis remains as an important cause of maternal mortality and is responsible for about 14/100.000 deaths per year (4). Jawad et al. (5) defined a mortality rate of $20-40 \%$ for potentially life threatening complications of acute infection as severe sepsis with acute organ dysfunction which increased to $60 \%$ if septic shock develops. Additionally, Netto et al. (6) found that 17\% of cases involving septic complications were diagnosed during pregnancy, $36 \%$ during childbirth and $47 \%$ of septic complications developed in the postpartum period. 
In 1991, the first recommendations to identify sepsis as a result of a systemic inflammatory response to infection (systemic inflammatory response syndrome) were given, reflecting the orders of the report by $\mathrm{Mi}$ nistry of Health of Ukraine which identified it as septic shock (7). The diagnosis of systemic inflammatory response syndrome (SIRS) is formulated in the presence of two of the four initial criteria for sepsis. It effects only the inflammatory response and is regarded as an extremely infectious process (8). The criteria include systemic inflammation, organ dysfunction, organ failure and cytokine storm (9). However, the validity of SIRS as a descriptor of sepsis pathobiology was challenged. The main reason for this is that the researches on the mechanism of sepsis revealed that it involved the activation of both pro-inflammatory and anti-inflammatory response. Significant changes occur not only in the immune system, but also in cardiovascular, nervous, hormonal, metabolic and coagulation systems. Changes in each of the systems have clinical significance $(10,11)$.

Based on these, in 2014, the Congress of the European Society of Intensive Care Medicine and Society of Critical Care Medicine decided to review the concept of sepsis. According to the new concept, sepsis was revised as the life threatening condition due to organ dysfunction and was defined by the changes in Sepsis-related Organ Failure Assessment (SOFA) score (12). Additionally, the recommendations by the Ministry of Health of Ukraine are currently being regulated and current national protocols suggest using Glasgow Coma Scale to determine the level of consciousness, that is also a variable in SOFA score (6).

Hospitalization due to sepsis generally occurs from the emergency department due to its acute severity and its number has been rapidly increasing. Since it is accounted for 215.000 deaths alone in the United States, management of its complications are of crucial importance (13). Despite the development of new methods in sepsis assessment such as Acute Physiology and Chronic Health Evaluation, Mortality Probability Model and Simplified Acute Physiology Score, SOFA score remains as the traditional means of individual assessment and manual evaluation method for sepsis (14, $15)$.

The aim of this study is to perform a comparative analysis of selected clinical, laboratory parameters, also the use of SOFA scores in the differential diagnosis of sepsis between relatively limited and generalized forms of postpartum septic complications.

\section{MATERIAL AND METHODS}

This retrospective study was approved by Scientific Research Ethics Committee of Zaporozhye State Medical University. The study included 34 patients who were hospitalized with a diagnosis of postpartum sepsis and pyo-septic diseases between 2013 and 2016 at the Gynecological Department of Zaporizhzhia Regional Clinical Hospital (ZRCH), which is the clinical base of the Department of Obstetrics and Gynecology, of Zaporizhzhia State Medical University. Patients were divided into two clinical groups. The first group consisted of 15 women who were all (according to clinical and laboratory examination) given the confirmed diagnosis of relatively limited postpartum inflammatory diseases (endometritis). The second group consisted of 19 women with generalized forms of postpartum inflammatory diseases (peritonitis, sepsis). The reproductive function of the clinical groups is summarized in Table 1.

\section{Table 1: Reproductive function in clinical groups.}

\begin{tabular}{|l|l|l|l|l|}
\hline \multirow{2}{*}{ Reproductive function } & \multicolumn{2}{|l|}{ Group 1 (n=15) } & \multicolumn{2}{l|}{ Group 2 (n=19) } \\
\cline { 2 - 6 } & $\begin{array}{l}\text { Number of } \\
\text { patients }\end{array}$ & $\%$ & $\begin{array}{l}\text { Number of } \\
\text { patients }\end{array}$ & $\%$ \\
\hline Nulliparic women & 1 & 6.67 & 1 & 5.26 \\
\hline Women who had a history of one childbirth & 7 & 46.67 & 11 & 57.89 \\
\hline $\begin{array}{l}\text { Women who had a history of two births and more } \\
\text { (multiparity) }\end{array}$ & 7 & 46.67 & 7 & 36.84 \\
\hline
\end{tabular}

The average age of the patients was $27.18 \pm 7.62$ years; $23.94 \pm 4.29$ years in the first group and $30.06 \pm 8.81$ years in the second group respectively.

Of the first group, 12 patients lived in rural parts and 3 patients lived in the urban part of Zaporizhzhia, whereas of the second group 12 patients lived in the countryside of the city and 7 in the urban part and cities around the region.

The clinical examination and laboratory results were obtained from patients' files. The data regarding the time of diagnosis of postpartum inflammatory disease, the cause and the management of postpartum septic complication and patients' follow-ups were recorded. Clinical and laboratory parameters including body temperature $\left({ }^{\circ} \mathrm{C}\right)$, hearth rate (beats/min), mean respiratory rate (breaths/min), the level of leukocytes were noted, that are mandatory parameters to be monitored during the general clinical examination of patients with postpartum purulent-inflammatory complications according to the orders of the Ministry of Health of Ukraine (7). 
To evaluate the diagnostic criteria of sepsis, we used SOFA and quick SOFA (qSOFA) scores in accordance with the recommendations of the Third International Consensus Definitions for Sepsis and Septic Shock (12). SOFA score used in the study consisted of 6 variables: partial pressure of oxygen, platelet count, level of consciousness set by Glasgow Coma Scale (6), bilirubin level, mean arterial pressure, serum creatinine level and urine output; while qSOFA scale based on 3 parameters: mean systolic arterial pressure, level of consciousness and mean respiratory rate. Total score of SOFA ranges from 0 to 24 points, whereas qSOFA from 0 to 3 points assigning one point for low systolic blood pressure $(\leq 100$ $\mathrm{mmHg}$ ), high respiratory rate ( $\geq 22$ breaths/min) and altered state of consciousness (Glasgow Coma Scale $<15$ ). The presence of qSOFA scores 2 points or more is associated with the high risk of death and extended intensive care unit length of stay (12). The necessary information to assess SOFA and qSOFA scores were obtained from patients' laboratory results.

Investigated values were interpreted as mean \pm standard deviation, numbers, and percentages. To assess the differences between selected clinical, laboratory parameters, SOFA and qSOFA scores of two independent groups, Mann-Whitney U test was used. All statistical procedures were performed with the use of STATISTICA Version 10.0 and Microsoft Excel 2010. P value of $<0.05$ was considered statistically significant.

\section{RESULTS}

Patients belonging to the first clinical group were transferred to a tertiary referral hospital with a diagnosis of postpartum endometritis on an average of $11.0 \pm$ 7.45 days after birth. The earliest diagnosis was given 3 days after birth (cesarian section) and the latest diagnosis was 27 days after birth. In 3 (20\%) cases complications arose after surgical cesarean section, 7 (46.67\%) cases had clinical and ultrasound data from placental tissue remains in the uterus, in $4(26.67 \%)$ cases SIRS was diagnosed.

All patients in the first group were administered a course of comprehensive anti-inflammatory, antibiotic therapy, which lasted an average of $7.0 \pm 2.0$ days. 8 (53\%) patients were administered with fluoroquinolones (ofloxacin, levofloxacin) in combination with metronidazole (ornidazole); for $3(20 \%)$ patients diagnosed with SIRS, antibiotic therapy was carried out using preparations of carbapenems (imipenem, meropenem) in combination with metronidazole (ornidazole).
From the clinical and ultrasound data it is evident that $7(46.67 \%)$ patients had placental residual remnants in the uterus which were removed using vacuum extraction, while in $2(28.57 \%)$ cases, the operation was carried out twice. With the comprehensive anti-inflammatory therapy, clinical data (Table 2), ultrasound and laboratory follow-up, the patients in the first group were discharged in satisfactory condition after an average of $11.8 \pm 5.25$ days of hospitalization and transferred to their permanent place of residence.

Patients belonging to the second clinical group were transferred to a tertiary referral hospital with various forms of generalized postpartum inflammatory disease on an average of $9.16 \pm 5.07$ days after delivery (cesarean section). In $6(31.58 \%)$ patients, complications arose after a late miscarriage, the average gestational period was $16.75 \pm 3.77$ weeks. In 5 (83.33\%) cases, septic complications developed associated with the background of missed pregnancy, in one (16.67\%) case after an incomplete spontaneous miscarriage. Overall the cause of the postpartum or postabortion sepsis was infected uterus in all 19 patients, as confirmed by pathomorphological examination. In 13 (68.42\%) cases, the generalized septic complication was developed in the postpartum period, while in $8(61.54 \%)$ patients after surgery (caesarean section) in $5(38.46 \%)$ patients after delivery. After clinical and laboratory examination (Table 2), in all cases, sepsis was diagnosed as a complication with a pan-metritis background. In all 8 patients who underwent delivery by cesarean surgery, postoperative failure of sutures was described according to clinical and laboratory tests and ultrasound results, which was confirmed intraoperatively. Also, in $4(21.05 \%)$ patients belonging to the second clinical group, sepsis occurred associated with the background of the manifestations of multiple organ failure syndrome (pneumonia, acute kidney injury) and 5 (26.32\%) patients were diagnosed with peritonitis.

Table 2: Clinical and laboratory parameters in the differential diagnosis of postpartum septic complications.

\begin{tabular}{|c|c|c|c|}
\hline $\begin{array}{lll}\text { Vital signs } & \text { during hospitalization in } \\
\text { Zaporizhzhia } & \text { Regional Clinical Hospital } \\
(\text { ZRCH }) & & \\
\end{array}$ & $\begin{array}{l}\text { Group } 1(n=15) \\
\text { Mean } \pm \text { Standard } \\
\text { Deviation }\end{array}$ & $\begin{array}{l}\text { Group } 2(n=19) \\
\text { Mean } \pm \text { Standard } \\
\text { Deviation }\end{array}$ & $\bar{p}$ \\
\hline Body temperature, ${ }^{\circ} \mathrm{C}$ & $38.19 \pm 0.52$ & $38.15 \pm 1.1$ & $p>0.05$ \\
\hline Heart rate (beats $/ \mathrm{min}$ ) & $91.6 \pm 8.35$ & $102.26 \pm 16.42$ & $p=0.00078$ \\
\hline The frequency of breathing (breaths $/ \mathrm{min}$ ) & $19.07 \pm 2.49$ & $24.16 \pm 5.09$ & $p=0.0164$ \\
\hline The number of leukocytes $\left(\times 10^{9} / \mathrm{L}\right)$ & $9.08 \pm 5.1$ & $10.6 \pm 7.4$ & $p>0.05$ \\
\hline
\end{tabular}


All patients in the second group underwent hysterectomy including the fallopian tubes as an urgent procedure followed by antibiotic group therapy with carbapenems (imipenem, meropenem) in combination with vancomycin or metronidazole and linezolid (ornidazole). After the surgery and complex anti-inflammatory therapy, 18 (94.74\%) patients with generalized postpartum septic complications were discharged with sufficient condition and placed under active ambulatory care in permanent place of residence. Average period of inpatient treatment was $17.84 \pm 8.39$ days. Despite a comprehensive anti-inflammatory and intensive care and three surgical procedures, one (5.26\%) patient died, associated with septic complications (severe sepsis, syndrome of multiple organ failure, iridocorneal endothelial syndrome) and diffuse peritonitis.

Fever was noted in all $34(100 \%)$ patients included in the study; $38.19 \pm 0.52^{\circ} \mathrm{C}$ in the first group; $38.15 \pm 1.1^{\circ} \mathrm{C}$ in the second group ( $\left.\mathrm{p}>0.05\right)$. Febrile values (over $38^{\circ} \mathrm{C}$ ) were measured in $10(66.67 \%)$ patients belonging to the first group and in 11 (57.89\%) patients belonging to the second group.

The data regarding the evaluation of heart rate obtained during the hospital stay of patients with suspected septic complications in the postpartum period showed following results: The group of patients with a mean heart rate of $91.6 \pm 8.35$ beats/ min were hospitalized with a clinical diagnosis of postpartum endometritis (group I) and the group of patients with a mean heart rate of $102.26 \pm 16.42$ beats/min had suspected generalized form of septic complications (group II) $(\mathrm{p}=0.00078)$.

Mean respiratory rate in the first clinical group was $19.07 \pm 2.49$ breaths/min during hospitalization in $\mathrm{ZRCH}$ and it was significantly lower than the second clinical group's rate which was recorded as $24.16 \pm 5.09$ breaths $/ \mathrm{min}(\mathrm{p}=0.0164)$.

Concerning the level of leukocytes; significant values of standard error of the mean and the lack of reliable difference on indicators of leukocytes in both clinical groups are noteworthy. In the first group, leukocyte level was $9.08 \pm 5.1 \times 10^{9}$ cells per liter and in the second clinical group, it was $10.6 \pm$ $7.4 \times 10^{9}$ cells per liter $(\mathrm{p}>0.05)$.

During the hospitalization of the patients in the admission department, the condition of patients were pre-evaluated with the qSOFA score to decide whether they should have been hospitalized at the intensive care unit and if there was a difference between the groups.

Analyzing the results in both clinical groups with regard to the qSOFA score, there was no significant difference in all three indices between the groups ( $p>0.05)$. Meanwhile, in the second clinical group, 2 (13.33\%) patients scored a total of 2 points on the qSOFA score (Table 3 ). They had been admitted to the intensive care unit for further treatment.

\section{Table 3: Results of clinical examination of patients} with the qSOFA score.

\begin{tabular}{|c|c|c|c|c|c|}
\hline \multirow[b]{2}{*}{ Indicators } & \multicolumn{2}{|l|}{ Group I ( $(n=15)$} & \multicolumn{2}{|l|}{ Group 2 ( $n=19)$} & \multirow[b]{2}{*}{$p$} \\
\hline & $\begin{array}{c}\text { Mean } \pm \text { Standard } \\
\text { Deviation(min-max) }\end{array}$ & \begin{tabular}{|l|}
$q S O F A=1$ \\
(Number of \\
patients)
\end{tabular} & $\begin{array}{c}\text { Mean + Standard } \\
\text { Deviation (min-max) }\end{array}$ & \begin{tabular}{|l|} 
SSOFA $=1$ \\
(Number of \\
patients)
\end{tabular} & \\
\hline $\begin{array}{l}\text { Systolic blood pressure } \\
\leq 100 \mathrm{~mm} \mathrm{Hg}\end{array}$ & $\begin{array}{l}121.33 \pm 13.16 \\
(110-160)\end{array}$ & 0 & $\begin{array}{l}116.05 \pm 13.9 \\
(90-130)\end{array}$ & 4 & $p>0.05$ \\
\hline Respiratory rate $\geq 22 / \mathrm{min}$ & $\begin{array}{l}17.9 \pm 0.32 \\
(17-18)\end{array}$ & 0 & $\begin{array}{l}21.46 \pm 6.46 \\
(14-36)\end{array}$ & 5 & $p>0.05$ \\
\hline $\begin{array}{l}\text { Altered mental status } \\
\text { (Glasgow Coma Scale) } \\
\text { <15points }\end{array}$ & $\begin{array}{l}14.93 \pm 0.26 \\
(14-15)\end{array}$ & 1 & \begin{tabular}{|l}
$14.24 \pm 1.44$ \\
$(10-15)$
\end{tabular} & 5 & $p>0.05$ \\
\hline $\begin{array}{l}S O F A \geq 2 \quad \text { points } \\
\text { (Number of patients) }\end{array}$ & 0 & & 2 & & \\
\hline
\end{tabular}

Min: Minimum Max: Maximum

During the first day of the hospitalization of the patients, regardless of their subsequent stay (in the intensive care unit or in the Department of Gynecology), SOFA score was used for the diagnosis of septic organ failure (Table 4). A SOFA score of 2 or more points indicates a multiple organ failure of the septic genesis.

Table 4: Results of examination of patients in clinical groups on the SOFA scale.

\begin{tabular}{|c|c|c|c|c|c|}
\hline \multirow[b]{2}{*}{ Indicator } & \multicolumn{2}{|l|}{ Group 1 ( $n=15)$} & \multicolumn{2}{|l|}{ Group $2(n=19)$} & \multirow[b]{2}{*}{$p$} \\
\hline & $\begin{array}{l}\text { Mcan } \pm \text { Standard } \\
\text { Deviation(min-max) }\end{array}$ & $\begin{array}{l}\text { SOFA } \geq I \\
\text { (Number of } \\
\text { patients) }\end{array}$ & $\begin{array}{l}\text { Mcan } \pm \text { Standard } \\
\text { Deviation(min-max) }\end{array}$ & $\begin{array}{l}\text { SOFA } \geq 1 \\
\text { (Number of } \\
\text { patients) }\end{array}$ & \\
\hline $\mathrm{PaO}_{2} / \mathrm{FiO}_{2}{ }^{*}$ & - & - & - & - & \\
\hline Platelets $\left(x \mid O^{i} / \mu L\right)$ & \begin{tabular}{|l|}
$360.0 \pm 120.93$ \\
$(210-497)$
\end{tabular} & 0 & $\begin{array}{l}259.0 \pm 148.84 \\
(72-504)\end{array}$ & 2 & $p>0.05$ \\
\hline Bilirubin $(\mu \mathrm{mol} / \mathrm{L})$ & $\begin{array}{l}12.79 \pm 2.89 \\
(9-20)\end{array}$ & 0 & $\begin{array}{l}11.08 \pm 2.94 \\
(6-16)\end{array}$ & 0 & $p>0.05$ \\
\hline $\begin{array}{c}\text { Mean arterial } \\
\text { pressure } \\
(m m \mathrm{Hg})\end{array}$ & $\begin{array}{l}91.11 \pm 7.45 \\
(83.3 ; 106.7)\end{array}$ & 0 & $\begin{array}{l}86.23 \pm 11.95 \\
(63.3-103.9)\end{array}$ & 3 & $p>0.05$ \\
\hline $\begin{array}{l}\text { Glasgow Coma } \\
\text { Scale score }\end{array}$ & $\begin{array}{l}14.93 \pm 0.26 \\
(14-15)\end{array}$ & 1 & \begin{tabular}{|l}
$14.23 \pm 1.44$ \\
$(10-15)$
\end{tabular} & 5 & $p>0.05$ \\
\hline $\begin{array}{c}\text { Creatinine } \\
(\mu \text { mol/L) }\end{array}$ & $\begin{array}{l}108.78 \pm 41.19 \\
(60-179)\end{array}$ & 4 & $\begin{array}{l}80.61 \pm 44.31 \\
(32-223)\end{array}$ & 1 & $p>0.05$ \\
\hline $\begin{array}{l}\text { Urine output } \\
\text { (mL/day) }\end{array}$ & \begin{tabular}{|l|}
$1277.33 \pm 84.8$ \\
$(1170-1450)$
\end{tabular} & 0 & $\begin{array}{l}1323,68 \pm 513,3 \\
(170-2600)\end{array}$ & 2 & $p>0.05$ \\
\hline
\end{tabular}

Min: Minimum Max: Maximum

* The ratio of $\mathrm{PaO} 2$ / FiO2 in relation to invasive risks (catheterization of the arterial vessel), was determined in patients of the second clinical group $(n=3)$ without further statistical processing of the results and without taking these values into account in the overall assessment of the number of points SOFA scale. 


\section{DISCUSSION}

In our study, the patient group with relatively limited postpartum inflammatory diseases and the group with generalized forms of postpartum inflammatory diseases were compared in terms of four indicators (body temperature, heart rate, respiratory rate and the number of leucocytes) with the data of Zaporizhzhia Regional Clinical Hospital, that were selected in accordance with clinical protocols of the Ministry of Health of Ukraine (7). The group of patients with a generalized form of postpartum sepsis had significantly higher mean heart rate $(102.26 \pm$ 16.42 beats $/ \mathrm{min})$ and mean respiratory rate $(24.16 \pm$ 5.09 breaths $/ \mathrm{min})(\mathrm{p}=0.00078, \mathrm{p}=0.0148)$. Considering these results, monitoring heart and respiratory rates may be crucial in the differential diagnosis of postpartum sepsis.

Alan Jones et al. (16) involved a clinical setting of 248 subjects in their study, suggested that compared to many outcome predicting models available in the everyday clinical practice, SOFA scale is simple, easy to interpret and ready to use in the patient bedside assessment. Their results validated the utility of the SOFA score for patients admitted to the emergency department.

In a study by Roberto Ceriani et al. (17) including 218 patients who underwent cardiothoracic surgery, the accuracy of SOFA score in describing the severity of complications was identified. They were unable to evaluate the scores in dying patients with the neurological parameter of SOFA score. They supported the accuracy of SOFA score and described it as a useful analytic scale for the evaluation of patients who need to be admitted to the intensive care unit or critical care unit. Their study concluded that this system should be included for a group analysis and not just being as a clinical scale, which is a making decision on individual patients.

Harrison et al. (18) validated the use of a computer program for the calculation of SOFA score provided an easy and accessible method for the clinical setting. They indicated the necessity of real-time calculation of the SOFA score to evaluate the patients in the intensive care unit.

Considering these results in the literature, in this study we aimed to investigate the efficiency of SOFA and qSOFA scales in the differential diagnosis of postpartum sepsis. However, SOFA and qSOFA score assessment results of the two patient groups indicate a lack of a significant difference in all indicators $(p>0.05)$. Despite this result it is found out that none of the patients in the first group received a total of two or more points in the SOFA score. In the second clinical group, there were 5 (26.32\%) patients who had 2 or more points on the SOFA scale. Out of which $2(10.53 \%)$ patients had 7 points on the SOFA scale and $3(15.79 \%)$ patients had 2 points on the SOFA scale, which allowed, in combination with other indicators, to evaluate their condition as sepsis. Moreover, only the second group had patients who had 2 points or more on the qSOFA scale, that is associated with high risk of death and extended intensive care unit length of stay (12).

Based on our results, we concluded that it is necessary to comprehensively assess the status of the patients according to the definition of sepsis based on SIRS criteria in combination with the SOFA score and qSOFA in order to timely diagnose postpartum septic complications $(6,7)$. Besides, patients with clinical and/or laboratory signs of postpartum septic complications must be transferred to a tertiary referral hospital within the first 24 hours. Moreover, all clinical cases within the postpartum period, demonstrating inflammatory processes of the uterus and signs of multiple organ failure should be regarded as a septic state. These cases may require urgent surgical intervention with hysterectomy and salpingectomy. We believe this clinical approach will allow an early differential diagnosis including localized and generalized forms of septic complications and ensure the clinical diagnosis of sepsis can be made at an optimal time with the subsequent provision of adequate treatment.

Ethics Committee Approval: This study was approved by Scientific Researches Committee of Zaporozhye State Medical University.

Informed Consent: Written informed consent was obtained from the participants of this study.

Conflict of Interest: The authors declared no conflict of interest.

Author contributions: Concept: PMI, VV. Design: PMI, VV. Supervision: PMI. Resources: PMI, VV. Materials: VV, PMI. Data collection and/or processing: VV, TV. Analysis and/or Interpretation: VV, TV. Literature Search: VV, TV. Writing Manuscript: VV. Critical Review: PMI, VV.

Financial disclosure: The authors declared that this study received no financial support. 


\section{REFERENCES}

1. World Health Organization, UNICEF, United Nations Population Fund and The World Bank. Trends in maternal mortality: 1990 to 2015. WHO, Geneva, 2015.

2. Lapinsky SE. Obstetric infections. Crit Care Clin 2013;29(3):509-20.

3. Slynko OM, Pavliuchenko MI, Mikhisor IP et al. Modern tactics of observation the postpartum purulent-septic complications. Zaporozhye Medical Journal 2014;2(83):69-71.

4. Central Intelligence Agency. Field listing: maternal mortality ratio. The world Factbook. Available from URL: https://www.cia.gov/library/publications/ the-world-factbook/fields/2223.html.

5. Jawad I, Lukšić I, Rafnsson SB. Assessing available information on the burden of sepsis: global estimates of incidence, prevalence and mortality. J Glob Health 2012;2(1):010404.

6. Netto CM, Whitten M, Shetty N. Postpartum sepsis. Br J Hosp Med 2015;76(8):118-21.

7. On approval of clinical protocols for obstetric and gynecological care. Order of the Ministry of Health of Ukraine: 2004 Dec. Report No: 676.

8. Cataldo R, Vennari M, Agro FE. Septic and septic shock. In: Agro FE, editor. Body Fluid Management From Physiology To Therapy. Springer; 2013.p.137-48.

9. Parson M. Cytokine storm in the pediatric oncology patient, differential diagnoses and workup. Journal of Peddanana 2010;27(5):253-8.

10. American College of Chest Physicians/Society of Critical Care Medicine Consensus Conference: Definitions for sepsis and organ failure and guidelines for the use of innovative therapies in sepsis. Critical Care Medicine 1992;20(6):864-74.

11. Knowles SJ, O'Sullivan NP, Meenan AM et al. Maternal sepsis incidence, etiology and outcome for mother and fetus: a prospective study. BJOG 2015;122(5):66371 .

12. Singer M, Deutschman CS, Seymour CW. The third international consensus definitions for sepsis and septic shock (sepsis-3). JAMA 2016;315(8):801-10.
13. Dombrovskiy VY, Martin AA, Sunderram J et al. Rapid increase in hospitalization and mortality rates for severe sepsis in the United States: a trend analysis from 1993 to 2003. Crit Care Med 2007;35:1244-50.

14. Torio CM, Moore BJ. National inpatient hospital costs: the most expensive conditions by payer, 2013. Rockville (MD) Healthcare Cost and Utilization Project (US). Agency for Healthcare Research and Quality: 2016 May. Statistical Brief: 204.

15. Zimmerman JE, Kramer AA, McNair DS et al. Acute physiology and chronic health evaluation (APACHE) IV: hospital mortality assessment for today's critically ill patients. Critical Care Medicine 2006;34(5):1297-310.

16. Jones AE, Trzeciak S, Kline JA. The sequential organ failure assessment score for predicting outcome in patients with severe sepsis and evidence of hypoperfusion at the time of emergency department presentation. Crit Care Med 2009;37(5):1649-54.

17. Ceriani R, Mazzoni M, Bortone F et al. Application of the sequential organ failure assessment score to cardiac-surgical patients. Chest 2003;123(4):1229-39.

18. Harrison A, Yadav H, Pickering BW et al. Validation of computerized automatic calculation of the sequential organ failure assessment score. Critical Care Research and Practice 2013;2013:975672. 